\title{
Association of ALOX5AP gene single nucleotide polymorphisms and cerebral infarction in the Han population of northern China
}

\author{
Shuang-yan Zhang ${ }^{1}$, Mei-ling Xu' ${ }^{1}$ Cui-e Zhang ${ }^{1 *}$, Zheng-yi Qu', Bin-bin Zhang ${ }^{1}$, Zu-yan Zheng ${ }^{2}$ \\ and Li-ming Zhang ${ }^{3}$
}

\begin{abstract}
Background: To explore the association of ALOX5AP single nucleotide polymorphisms (SNPs) and haplotype with the occurrence of cerebral infarction in the Han population of northern China.

Methods: Blood samples were collected from 236 patients of Han ancestry with a history of cerebral infarction and 219 healthy subjects of Han ancestry with no history of cerebral infarction or cardiovascular disease. Applied Biosystems ${ }^{\circledR}$ TaqMan ${ }^{\circledR}$ SNP Genotyping Assays for SNP genotyping were used to determine the genotypes of 7 ALOX5AP SNP alleles (rs4073259, rs4769874, rs9315050, rs9551963, rs10507391, rs9579646, and rs4147064).

Results: One SNP allele (A) of rs4073259 was significantly associated with development of cerebral infarction $(P=0.049)$. In comparison to control groups, haplotype rs9315050\&rs9551963 AAAC [OR (95\% Cl) =1.53 (1.02-2.29)], and genotypes rs4147064 CT [OR (95\% Cl) $=1.872(1.082-3.241)]$, and rs9551963 AC [OR $(95 \% \mathrm{Cl})=2.015(1.165-$ 3.484)] increased the risk of cerebral infarction in patients with hypertension. Genotype rs9579646 GG [OR (95\% $\mathrm{Cl})=2.926(1.18-7.251)]$ increased the risk of, while rs $4073259 \mathrm{GG}[\mathrm{OR}(95 \% \mathrm{Cl})=0.381(0.157-0.922)]$ decreased the risk of cerebral infarction in patients with diabetes.

Conclusion: These results suggest the ALOX5AP SNP A allele in rs4073259 and genotype rs9579646 GG, rs9551963 AC, and haplotype rs9315050 \& rs9551963 AAAC were associated with an increased risk of ischemic stroke in the Han population, while rs4073259 GG was associated with a decreased risk.
\end{abstract}

Keywords: Cerebral infarction, ALOX5AP, FLAP, Han ethnicity, SNP

\section{Background}

Multiple studies have shown associations between variants of the 5-lipoxygenase activating protein gene $(A L O X 5 A P)$ and risk for ischemic stroke and myocardial infarction (MI) [1-9]. Two at-risk haplotypes (HapA and HapB) for stroke had been identified in the ALOX5AP gene $[1,10]$. The single nucleotide polymorphisms (SNPs) associated with HapA are rs17222814, rs10507391, rs4769874, and rs9551963, and those associated with the HapB are rs17216473, rs10507391, rs9315050, and rs17222842. Different studies, however, reported conflicting results. The association of a 4-

\footnotetext{
* Correspondence: Zhangcuie142@163.com

'Department of Neurology, The Fourth Affiliated Clinical College, Harbin Medical University, Yiyuan Street 37, Nangang District, Harbin, China Full list of author information is available at the end of the article
}

marker SNP haplotype in ALOX5AP with approximately 2-times increased risk of ischemic stroke and myocardial infarction was reported in an Icelandic population [1]. A similar risk of stroke was found in Chinese males [5], Japanese [8], and Europeans [2]. On the contrary, a study found no association of ALOX5AP variants with risk of MI or stroke in the United States (US) by Zee et al. [6], whereas another study in the US by Kaushal et al. [9] found a significant association with stroke among whites, but no association among blacks. These reports suggest that there might be variations between the populations of different ancestries in the association between ALOX5AP genetic variants and risk of stroke.

The purpose of this study was to study the possible association of 7 variants of ALOX5AP, rs4073259, rs4769874, rs9315050, rs9551963, rs10507391, rs9579646,

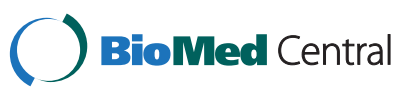


and rs4147064 with ischemic stroke in the population with Han ancestry in northern China.

\section{Material and methods Subjects}

The subjects included in this study were patients diagnosed with cerebral infarction from three hospitals including the Second Affiliated Hospital of Harbin Medical University, the Forth Affiliated Clinical Hospital of Harbin Medical University, and the First Affiliated Hospital of Harbin Medical University from October 2004 to May 2010. All cases were diagnosed using the Fourth edition of Cerebrovascular Disease Diagnostic Standards [11]. Patients who had endocrine related diseases, metabolic disorders, tumors, and cerebral hemorrhage were excluded from this study. The control group was composed of subjects who did not have cerebrovascular diseases themselves, and no family history of cerebrovascular diseases for a minimum of three generations. All the subjects in this study were from different families of Han ethnicity whose families have lived in the Northeastern part of China, including Heilongjiang, Jilin and Liaoning, for more than 3 generations. This study was approved by the Institutional Review Board of the Fourth Affiliated Clinical Hospital of Harbin Medical University and each participant provided written informed consent.

\section{DNA extraction and genotyping}

DNA was extracted in a standard manner. Applied Biosystems ${ }^{\circledR}$ TaqMan ${ }^{\circledR}$ SNP Genotyping Assays were used for SNP genotyping following the manufacturer's instructions. In brief, one to $20 \mathrm{ng}$ template DNA dissolved in $2.25 \mu \mathrm{L}$ volume each well was loaded into 384well plates for PCR. The reaction volume a total of $5 \mu \mathrm{L}$ included 2.5 $\mu \mathrm{L}$ TaqMan Universal PCR master Mix (2x) and $0.25 \mu \mathrm{L} 10 \times$ working stock of SNP genotyping assay buffer. The PCR reaction conditions were $95{ }^{\circ} \mathrm{C}$ for $10 \mathrm{~min}$ followed by 60 cycles of $92{ }^{\circ} \mathrm{C}$ for $15 \mathrm{sec}$ and $60{ }^{\circ} \mathrm{C}$ for $1 \mathrm{~min}$ in an ABI 9700 PCR instrument. The genotyping data were collected by the ABI 9700 instrument. During SNP genotyping, duplicates/positive/negative controls were used as previously described [12].

Of the 4 HapA SNPs (rs17222814, rs10507391, rs4769874, and rs9551963), rs17222814 was not selected because in our preliminary study this SNP was shown to be almost monomorphic in the Chinese population. Thus, we selected 3 SNPs rs10507391, rs4769874, and rs9551963 from HapA for this study. Of the 4 HapB SNPs (rs17216473, rs10507391, rs9315050, and rs17222842), rs17222842 was excluded because it is monomorphic in the Chinese population, and rs17216473 was not selected because no significant association with stroke was noted in a preliminary study. The SNPs rs9579646 and rs4147064 were selected because they showed weak association with stroke in Israeli [2] and middle European populations [13], and rs4073259 was found to be associated with stroke in a preliminary study [12].

\section{Statistical analysis}

Data are presented as mean \pm standard deviation or number (percentage). Hardy-Weinberg equilibrium (HWE) testing was carried out for all 7 SNPs. Single markers in association with the disease were assessed using $\chi 2$ tests in Haploview Version 4.2 (Broad Institute, Cambridge, MA, USA). Odds ratios (ORs) and 95\% confidence intervals (CIs) were calculated using logistic regression analysis. Statistical analysis was performed using by SPSS version 15.0 statistical software (SPSS, Inc., Chicago, IL, USA). A value of $P<0.05$ was considered statistically significant.

\section{Results}

\section{Patient demographics and disease characteristics}

The characteristics of ischemic stroke patients and controls are summarized in Table 1. Patients with ischemic stroke were older and had higher triglyceride level than the controls (both $P<0.001)$. About $16.5 \%(\mathrm{n}=39)$, $37.3 \%(\mathrm{n}=88)$, and $22.9 \%(\mathrm{n}=54)$ of patients with ischemic stroke had also heart disease, hypertension or diabetes, respectively, while no control had these diseases (All $P<0.001$ ). Cholesterol levels and gender distribution were not different between the groups.

$$
\text { rs9579646/SG13S106 G } 211 \text { (48) 258(55) } 0.0504
$$

\section{Univariate analysis of SNP distribution between ischemic stroke patients and controls}

The allele distribution of 7 SNPs of ALOX5AP was summarized in Table 2. Only the frequency of rs4073259 SNP allele A was significantly different between ischemic stroke patients and the controls $(48 \%$ vs $54 \%$, $P=0.049$ ). The frequency of rs 9579646 allele $\mathrm{G}$ had a marginal $\mathrm{p}$ value between the two groups ( $48 \%$ vs $55 \%$, $P=0.0504)$.

Table 1 Patient demographics and disease characteristics

\begin{tabular}{llll}
\hline & $\begin{array}{l}\text { Ischemic Stroke } \\
\text { Subjects }(\boldsymbol{n = 2 3 6 )}\end{array}$ & $\begin{array}{l}\text { Healthy Control } \\
\text { Subjects }(\boldsymbol{n}=\mathbf{2 1 9})\end{array}$ & $\boldsymbol{P}$ \\
\hline Age (y) & $62.86 \pm 11.34$ & $50.36 \pm 10.21$ & $<0.001^{*}$ \\
Triglycerides & $1.75 \pm 1.42$ & $1.38 \pm 0.93$ & $<0.001^{*}$ \\
Cholesterol & $5.07 \pm 1.16$ & $5.00 \pm 1.01$ & 0.503 \\
Male & $125(57.1)$ & $145(61.4)$ & 0.390 \\
Heart disease & $39(16.5)$ & 0 & $<0.001^{*}$ \\
Hypertension & $88(37.3)$ & 0 & $<0.001^{*}$ \\
Diabetes & $54(22.9)$ & 0 & $<0.001^{*}$ \\
\hline
\end{tabular}

Data are presented as mean \pm standard deviation or number (percentage). 
Table 2 The association of ALOX5AP SNP allele with ischemic stroke in northern Han Chinese

\begin{tabular}{|c|c|c|c|c|c|}
\hline$\#$ & Public Name/SNP Name & Allele & Control Group $(n=219)$ & Case Group $(n=236)$ & $P$ \\
\hline \multirow[t]{2}{*}{1} & rs4147064/SG13S137 & $\mathrm{T}$ & $148(34)$ & $186(39)$ & 0.0882 \\
\hline & & C & $288(66)$ & $286(61)$ & \\
\hline \multirow[t]{2}{*}{2} & rs9579646/SG13S106 & G & $211(48)$ & $258(55)$ & 0.0504 \\
\hline & & A & $227(52)$ & $214(45)$ & \\
\hline \multirow[t]{2}{*}{3} & rs4073259/SG13S100 & A & $208(48)$ & $255(54)$ & 0.0487 \\
\hline & & G & $230(53)$ & $217(46)$ & \\
\hline \multirow[t]{2}{*}{4} & rs10507391/SG13S114 & $\mathrm{T}$ & $269(62)$ & $304(64)$ & 0.3979 \\
\hline & & $A$ & $167(38)$ & $168(36)$ & \\
\hline \multirow[t]{2}{*}{5} & rs4769874/SG13S89 & G & 429 (98) & $464(98)$ & 0.6887 \\
\hline & & A & $9(2)$ & $8(2)$ & \\
\hline \multirow[t]{2}{*}{6} & rs9315050/SG13S41 & A & $429(98)$ & $464(98)$ & 0.6887 \\
\hline & & G & $9(2)$ & $8(2)$ & \\
\hline \multirow[t]{2}{*}{7} & rs9551963/SG13S32 & C & $147(34)$ & $188(4)$ & 0.0564 \\
\hline & & $A$ & $289(66)$ & $284(60)$ & \\
\hline
\end{tabular}

Data are presented as numbers (percentages).

Then, the genotype distribution of ALOX5AP SNP in the ischemic stroke and the control groups is calculated (Table 3). Individuals with a genotype of rs9551963 AC or a genotype of rs9579646 GG had higher risks of developing a cerebral infarction than individuals with genotype rs9551963 AA or genotype rs9579646 AA (OR $=1.50$ (1.01-2.24), $\quad P=0.046, \quad \mathrm{OR}=1.73 \quad(1.01-2.97), \quad P=0.047$, respectively), But individuals with a genotype of GG in the rs4073259 SNP had a lower risk (0.57-fold) of developing a cerebral infarction than individuals with the AA genotype (95\% CI 0.33-0.98, P = 0.044).

For further analysis, a comparison of genotype distribution between the control group and case subgroups stratified into heart disease $(n=39)$, hypertension $(n=88)$, and

Table 3 Genotype distribution in the stroke and control groups

\begin{tabular}{|c|c|c|c|c|c|c|}
\hline$\#$ & Public Name & Genotype & Control Group $(n=219)$ & Case Group $(n=236)$ & OR $(95 \% \mathrm{Cl})$ & $P$ \\
\hline \multirow[t]{3}{*}{1} & rs4147064 & $\mathrm{CC}$ & $97(44)$ & $85(36)$ & Ref & - \\
\hline & & CT & $94(43)$ & $116(49)$ & $1.41(0.95-2.10)$ & 0.092 \\
\hline & & $\pi$ & $27(12)$ & $35(15)$ & $1.48(0.83-2.64)$ & 0.186 \\
\hline \multirow[t]{3}{*}{2} & rs9579646 & AA & $55(25)$ & $46(19)$ & Ref & - \\
\hline & & $A G$ & $117(53)$ & $122(52)$ & $1.26(0.79-2.01)$ & 0.336 \\
\hline & & GG & $47(21)$ & $68(29)$ & $1.73(1.01-2.97)$ & $0.047^{*}$ \\
\hline \multirow[t]{3}{*}{3} & rs4073259 & AA & $45(21)$ & $66(28)$ & Ref & - \\
\hline & & $A G$ & $118(54)$ & $123(52)$ & $0.72(0.45-1.13)$ & 0.152 \\
\hline & & GG & $56(26)$ & $47(20)$ & $0.57(0.33-0.98)$ & $0.044^{*}$ \\
\hline \multirow[t]{3}{*}{4} & rs10507391 & AA & $31(14)$ & $28(12)$ & Ref & - \\
\hline & & AT & $105(48)$ & $112(47)$ & $1.18(0.66-2.10)$ & 0.571 \\
\hline & & $\pi$ & $82(38)$ & $96(41)$ & $1.30(0.72-2.34)$ & 0.389 \\
\hline \multirow[t]{2}{*}{5} & rs4769874 & $A G$ & $9(4)$ & $8(3)$ & Ref & - \\
\hline & & GG & $210(96)$ & $228(97)$ & $1.09(0.40-2.95)$ & 0.872 \\
\hline \multirow[t]{2}{*}{6} & rs9315050 & AA & $210(96)$ & $228(97)$ & Ref & - \\
\hline & & $A G$ & $9(4)$ & $8(3)$ & $0.92(0.34-2.50)$ & 0.872 \\
\hline \multirow[t]{3}{*}{7} & rs9551963 & AA & $99(45)$ & $84(36)$ & Ref & - \\
\hline & & $A C$ & $91(42)$ & $116(49)$ & $1.50(1.01-2.24)$ & $0.046^{*}$ \\
\hline & & CC & $28(13)$ & $36(15)$ & $1.52(0.85-2.69)$ & 0.155 \\
\hline
\end{tabular}

Data are presented as numbers (percentages) or odds ratio (OR) with $95 \%$ confidence interval $(\mathrm{Cl})$.

*Significant difference between control and case groups $(P<0.05)$. 


\begin{tabular}{|c|c|c|c|c|c|c|c|c|c|}
\hline \multirow[t]{2}{*}{$\#$} & \multirow{2}{*}{$\begin{array}{l}\text { Public } \\
\text { Name }\end{array}$} & \multirow[t]{2}{*}{ Genotype } & \multirow{2}{*}{$\begin{array}{l}\text { Control } \\
(n=219)\end{array}$} & \multicolumn{2}{|c|}{ Heart disease $(n=39)$} & \multicolumn{2}{|c|}{ Hypertension $(n=88)$} & \multicolumn{2}{|l|}{ Diabetes $(n=54)$} \\
\hline & & & & OR $(95 \% \mathrm{Cl})$ & $P$ & OR $(95 \% \mathrm{Cl})$ & $P$ & OR $(95 \% \mathrm{Cl})$ & $P$ \\
\hline \multirow[t]{3}{*}{1} & rs4147064 & CC & $97(44 \%)$ & 1 & & 1 & & 1 & \\
\hline & & CT & $94(43 \%)$ & $1.096(0.523-2.296)$ & 0.8072 & $1.872(1.082-3.241)$ & $0.0251^{*}$ & $1.548(0.8-2.995)$ & 0.195 \\
\hline & & $\pi$ & $27(12 \%)$ & $1.347(0.481-3.776)$ & 0.5707 & $1.596(0.715-3.562)$ & 0.2534 & $1.796(0.725-4.448)$ & 0.2055 \\
\hline \multirow[t]{3}{*}{2} & rs9579646 & $\mathrm{AA}$ & $55(25 \%)$ & 1 & & 1 & & 1 & \\
\hline & & $A G$ & 117 (53\%) & $1.067(0.437-2.604)$ & 0.8871 & $1.171(0.612-2.24)$ & 0.6326 & $1.541(0.655-3.623)$ & 0.3215 \\
\hline & & GG & $47(21 \%)$ & $1.902(0.726-4.981)$ & 0.1908 & $1.996(0.977-4.077)$ & 0.0578 & $2.926(1.18-7.251)$ & $0.0204^{*}$ \\
\hline \multirow[t]{3}{*}{3} & rs4073259 & $\mathrm{AA}$ & $45(21 \%)$ & 1 & & 1 & & 1 & \\
\hline & & AG & $118(54 \%)$ & $0.533(0.241-1.176)$ & 0.1189 & $0.591(0.328-1.062)$ & 0.0787 & $0.526(0.266-1.043)$ & 0.066 \\
\hline & & GG & $56(26 \%)$ & 0.495 (0.189-1.297) & 0.1523 & $0.488(0.238-1.001)$ & 0.0504 & $0.381(0.157-0.922)$ & $0.0324^{*}$ \\
\hline \multirow[t]{3}{*}{4} & rs10507391 & $\mathrm{AA}$ & $31(14 \%)$ & 1 & & 1 & & 1 & \\
\hline & & AT & $105(48 \%)$ & $1.475(0.469-4.64)$ & 0.5058 & $0.84(0.398-1.776)$ & 0.6485 & $1.771(0.571-5.493)$ & 0.3221 \\
\hline & & $\pi$ & $82(38 \%)$ & $1.417(0.436-4.601)$ & 0.5619 & $1.105(0.52-2.347)$ & 0.7949 & $2.457(0.793-7.614)$ & 0.1192 \\
\hline \multirow[t]{2}{*}{5} & rs4769874 & $A G$ & $9(4 \%)$ & 1 & & 1 & & 1 & \\
\hline & & GG & $210(96 \%)$ & $0.704(0.144-3.448)$ & 0.6655 & $1.079(0.28-4.166)$ & 0.9118 & $0.647(0.166-2.526)$ & 0.5312 \\
\hline \multirow[t]{2}{*}{6} & rs9315050 & $\mathrm{AA}$ & $210(96 \%)$ & 1 & & 1 & & 1 & \\
\hline & & $A G$ & $9(4 \%)$ & $1.42(0.29-6.949)$ & 0.6655 & $0.926(0.24-3.576)$ & 0.9118 & $1.545(0.396-6.029)$ & 0.5312 \\
\hline \multirow[t]{3}{*}{7} & rs9551963 & $\mathrm{AA}$ & 99 (45\%) & 1 & & 1 & & 1 & \\
\hline & & $A C$ & $91(42 \%)$ & $1.156(0.552-2.422)$ & 0.701 & $2.015(1.165-3.484)$ & $0.0122^{*}$ & $1.792(0.92-3.489)$ & 0.0863 \\
\hline & & $\mathrm{CC}$ & $28(13 \%)$ & $1.326(0.474-3.706)$ & 0.5906 & $1.44(0.636-3.261)$ & 0.3813 & $1.872(0.753-4.652)$ & 0.1771 \\
\hline
\end{tabular}

Data are presented as numbers (percentages) or odds ratios (OR) with $95 \%$ confidence interval $(\mathrm{Cl})$.

*Significant differences between controls and case subgroups $(P<0.05)$.

diabetes $(\mathrm{n}=54)$ is shown in Table 4 . In comparison to controls, rs4147064 genotype CT [OR (95\%CI) $=1.872$ (1.082-3.241)] and rs9551963 genotype AC [OR (95\% CI = 2.015 (1.165-3.484)] were positively significantly associated with cerebral infarction in patients with hypertension. Genotype rs9579646 GG [OR (95\% CI) $=2.926$ (1.187.251)] was positively significantly associated with, while genotype rs4073259 GG [OR $(95 \%$ CI $)=0.381$ (0.1570.922)] was negatively significantly associated with cerebral infarction in patients with diabetes.

\section{Analysis of haplotype distribution between ischemic stroke patients and controls}

The haplotype distribution in the stroke and control groups are shown in Table 5. Patients with haplotype rs9315050\&rs9551963 AAAC had a higher risk to have ischemic stroke than haplotype rs9315050\&rs9551963 AAAA $(\mathrm{OR}=1.53(1.02-2.29), P=0.041)$.

We further did linkage disequllibrium analysis and found significant linkage between rs9315050 vs. rs9551963, rs4073259 vs. rs10507391, and rs9579646 vs. rs4147064 $\left(D^{\prime}=1.0, D^{\prime}=0.911\right.$, and $D^{\prime}=0.376$, respectively, Figure 1).

\section{Discussion}

Our findings indicate that the A allele in rs4073259 is markedly increased in cerebral infarction patients in comparison to control subjects of Han ancestry in northern China. Genotype rs9579646 GG and rs9551963 AC were positively, while rs4073259 GG was negatively associated with cerebral infarction. Haplotypes rs9315050 \& rs9551963 AAAC were positively associated with cerebral infarction. Furthermore, genotypes rs4147064 CT and rs9551963 AC were associated with cerebral infarction in patients with hypertension, while rs9579646 GG and rs4073259 GG were associated with cerebral infarction in patients with diabetes. The findings suggest that SNP rs4073259 of the ALOX5AP gene is associated with developing cerebral infarction in this cohort, although the possibility that it is a functional variant cannot be ruled out. Although we found no marked difference in the frequency of alleles of other ALOX5AP SNPs tested between the control and case groups studied, we found significant differences of genotype frequency of other ALOX5AP SNPs between the control and case subjects, suggesting that they might play a role in the pathogenesis of cerebral infarction in the Han population of northern China. 
Table 5 Haplotype distribution in the stroke and control groups

\begin{tabular}{|c|c|c|c|c|c|}
\hline Public Name & Haplotype & Control Groups $(n=219)$ & Case Groups $(n=236)$ & OR $(95 \% \mathrm{Cl})$ & $P$ \\
\hline \multirow[t]{9}{*}{ rs4147064 \& rs9579646 } & CCAA & $36(17 \%)$ & $26(11 \%)$ & Ref & - \\
\hline & CCAG & $50(23 \%)$ & $40(17 \%)$ & $1.11(0.58-2.13)$ & 0.759 \\
\hline & CCGG & $11(5 \%)$ & $19(8 \%)$ & $2.39(0.98-5.87)$ & 0.057 \\
\hline & CTAA & $15(7 \%)$ & $20(8 \%)$ & $1.85(0.80-4.27)$ & 0.152 \\
\hline & CTAG & $53(24 \%)$ & $64(27 \%)$ & $1.67(0.90-3.12)$ & 0.105 \\
\hline & CTGG & $26(12 \%)$ & $32(14 \%)$ & $1.70(0.83-3.51)$ & 0.148 \\
\hline & TTAA & $4(2 \%)$ & $0(0 \%)$ & - & - \\
\hline & TTAG & $13(6 \%)$ & $18(8 \%)$ & $1.92(0.80-4.59)$ & 0.144 \\
\hline & TTGG & $10(5 \%)$ & $17(7 \%)$ & $2.35(0.93-5.97)$ & 0.071 \\
\hline \multirow[t]{8}{*}{ rs4073259 \& rs 10507391} & AAAT & $6(3 \%)$ & $2(1 \%)$ & Ref & - \\
\hline & AATT & $39(18 \%)$ & $64(27 \%)$ & $4.92(0.95-25.61)$ & 0.058 \\
\hline & AGAA & $2(1 \%)$ & $3(1 \%)$ & $4.50(0.41-49.63)$ & 0.219 \\
\hline & AGAT & $75(34 \%)$ & $90(38 \%)$ & $3.60(0.71-18.36)$ & 0.123 \\
\hline & AGTT & $40(18 \%)$ & $30(13 \%)$ & $2.25(0.42-11.94)$ & 0.341 \\
\hline & GGAA & $29(13 \%)$ & $25(11 \%)$ & $2.59(0.48-13.98)$ & 0.27 \\
\hline & GGAT & $24(11 \%)$ & $20(8 \%)$ & $2.50(0.45-13.78)$ & 0.293 \\
\hline & GGTT & $3(1 \%)$ & $2(1 \%)$ & $2.00(0.18-22.06)$ & 0.571 \\
\hline \multirow[t]{5}{*}{ rs9315050 \& rs9551963 } & AAAA & $99(45 \%)$ & $84(36 \%)$ & Ref & - \\
\hline & AAAC & 85 (39\%) & $110(47 \%)$ & $1.53(1.02-2.29)$ & $0.041^{*}$ \\
\hline & AACC & $26(12 \%)$ & $34(14 \%)$ & $1.54(0.86-2.77)$ & 0.149 \\
\hline & AGAC & $6(3) \%$ & $6(3 \%)$ & $1.18(0.37-3.79)$ & 0.783 \\
\hline & AGCC & $2(1 \%)$ & $2(1 \%)$ & $1.18(0.16-8.55)$ & 0.871 \\
\hline
\end{tabular}

Data are presented as numbers (percentages) or odds ratios (OR) with $95 \%$ confidence interval (CI).

*Significant differences between control and case groups $(P<0.05)$.

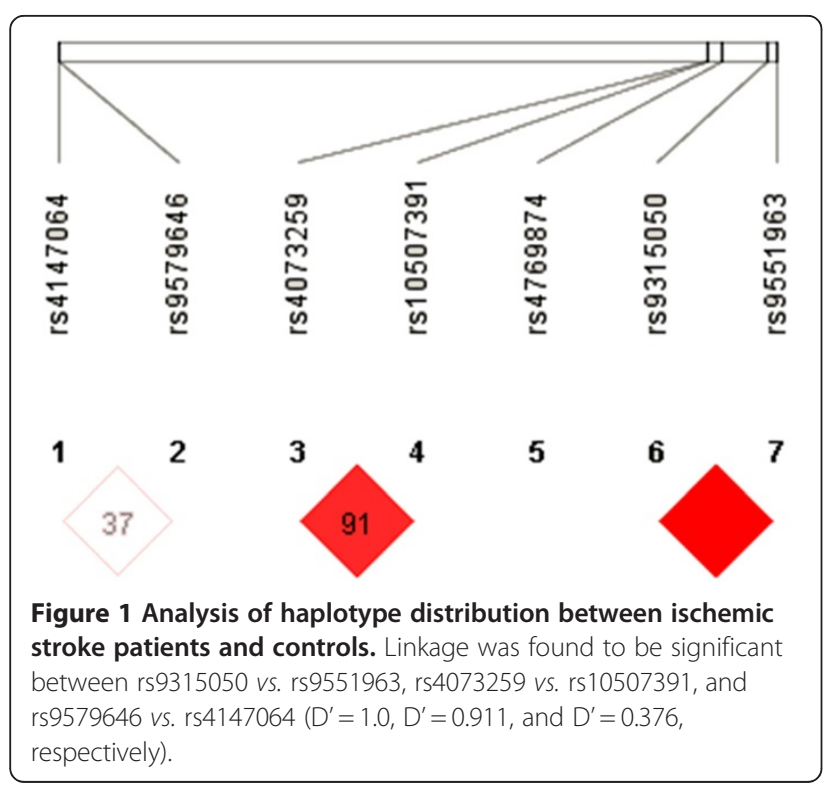

Microarray assays have revealed positive linkage domains associated with cardiovascular and cerebrovascular diseases which locate at 13p12-13 [1-3,10,14]. The ALOX5AP gene is located at bands 2 and 3 of region 1 of the long arm of chromosome 13, and encodes 5lipoxygenase activating protein (FLAP) which regulates the synthesis of leukotrienes [15]. An increase in the production of leukotrienes and resulting inflammatory changes in local blood vessels may be associated with development of atherosclerosis [4,16-19]. Whether the rs4073259 SNP alters FLAP warrants further study.

The association between the genetic polymorphism of ALOX5AP and the occurrence of cerebral infarction has been previously reported, but discrepancies between studies carried out in different populations have been noted. For example, Kaushal et al. [9] found that rs957646 and rs769874 were significantly associated with stroke in whites in the US, but no association was found in blacks. Another US study by Zee et al. [6] found no association of HapA or Hap B with stroke. Meschia et al. [4] found no association of ALOX5AP variants and ischemic stroke in a US population, Zhang et al. [5] reported the ALOX5AP variant SG13S114T/A was 
associated with increased risk of stroke in Chinese males, and Linsel-Nitschke et al. [20] found HapB was associated with an increased risk of myocardial infarction in a German population. Ji et al. [21] in a recent study reported that the -581_582 Ins A polymorphism in ALOX5AP might be a genetic risk factor for ischemic stroke in the Chinese Han population. The lack of consistency in available studies also suggests a limit of the analytical methodologies used in these studies, the population association test. A better refined methodology, such as the Family base association test (FBAT), may be needed to provide consistent results [22].

Zintaras et al. [13] performed a meta-analysis in 2009 including all studies of ALOX5AP genotyping (5,194 stroke cases and 4,566 controls). The authors found significant heterogeneity among studies $(\mathrm{PQ}=0.03$, $\mathrm{I} 2=63 \%$ ), a non-significant association between the HapA and stroke risk (random-effects $[R E]$ OR $=1.13$, 95\% CI 0.88-1.45), and no association of HapB with stroke risk $(\mathrm{RE} O \mathrm{OR}=1.03,95 \% \mathrm{CI} 0.77-1.37)$. They also reported that the SG13S114, SG13S89, SG13S25, SG13S32, SG13S35, and SG13S42 polymorphisms were not associated with stroke. The authors concluded that to date, the cumulated evidence did not support an association of $A L O X 5 A P$ variants and risk of stroke, though they cautioned that the conclusion was based on a relatively small number of studies.

The primary limitation of this study is the relatively low case number, especially in stratification based on genotypes. Further study with a larger population is required to confirm the findings. In addition, we did not study SNPs from other susceptible genes, e.g., phosphodiesterase 4D (PDE4D) in which some of the SNPs have been shown to be associated with the development of cerebral infarction [4].

\section{Conclusions}

In summary, our results indicate the ALOX5AP SNP A allele in rs4073259, genotype rs9579646 GG, rs9551963 AC, and haplotype rs9315050\&rs9551963 AAAC were associated with an increased risk of ischemic stroke in the Han population, while rs4073259 GG was associated with a decreased risk. Genotype rs4147064 CT and rs9551963 AC were positively significantly associated with cerebral infarction in patients with hypertension while genotype rs9579646 GG was positively significantly associated with, while genotype rs4073259 GG was negatively significantly associated with, cerebral infarction in patients with diabetes. However, more studies with large sample size are needed to detect the extended haplotype, and further confirm whether other SNPs of the ALOX5AP gene are associated with cerebral infarction.

\section{Competing interests}

The authors declare they have no competing interests.

\section{Authors' contributions}

We declare that all the listed authors have participated actively in the study, and all meet the requirements of the authorship. Dr. SZ designed the study and wrote the protocol. Dr. CZ performed research. Dr. MX contributed important reagents. Dr. CZ, Dr. ZQ, and Dr. ZZ managed the literature searches and analyses. Dr. SZ performed the statistical analysis. Dr. SZ wrote the first draft of the manuscript. BZ acquired blood samples. Dr LZ supervised the whole study. All authors read and approved the final manuscript.

\section{Funding}

This study was funded by the Provincial Health Department of Heilongjiang Province, (project numbers 2006-207), the Provincial Science and Technology Department of Heilongjiang Province (project number GC08C411), and the Provincial Education Department of Heilongjiang Province (project number 11521139).

\section{Author details}

'Department of Neurology, The Fourth Affiliated Clinical College, Harbin Medical University, Yiyuan Street 37, Nangang District, Harbin, China. 2Department of Neurology, The First Affiliated Hospital Heilongjiang, University of Chinese Medicine, Heping Road 26, Xiangfang District, Harbin, China. ${ }^{3}$ Department of Neurology, The First Affiliated Clinical College, Harbin Medical University, Youzheng Street 23, Nangang District, Harbin, China.

Received: 22 December 2011 Accepted: 12 July 2012

Published: 31 July 2012

\section{References}

1. Helgadottir A, Manolescu A, Thorleifsson G, Gretarsdottir S, Jonsdottir H, Thorsteinsdottir U, Samani NJ, Gudmundsson G, Grant SF, Thorgeirsson G, Sveinbjornsdottir S, Valdimarsson EM, Matthiasson SE, Johannsson $H$, Gudmundsdottir O, Gurney ME, Sainz J, Thorhallsdottir M, Andresdottir M, Frigge ML, Topol EJ, Kong A, Gudnason V, Hakonarson H, Gulcher JR, Stefansson $\mathrm{K}$ : The gene encoding 5-lipoxygenase activating protein confers risk of myocardial infarction and stroke. Nat Genet 2004, 36:233-239.

2. Lõhmussaar E, Gschwendtner A, Mueller JC, Org T, Wichmann E, Hamann G, Meitinger T, Dichgans M: ALOX5AP gene and the PDE4D gene in a central European population of stroke patients. Stroke 2005, 36:731-736.

3. Helgadottir A, Manolescu A, Helgason A, Thorleifsson G, Thorsteinsdottir U, Gudbjartsson DF, Gretarsdottir S, Magnusson KP, Gudmundsson G, Hicks A, Jonsson T, Grant SF, Sainz J, O'Brien SJ, Sveinbjornsdottir S, Valdimarsson EM, Matthiasson SE, Levey Al, Abramson JL, Reilly MP, Vaccarino V, Wolfe ML, Gudnason V, Quyyumi AA, Topol EJ, Rader DJ, Thorgeirsson G, Gulcher $J R$, Hakonarson $H$, Kong A, Stefansson K: A variant of the gene encoding leukotriene A4 hydrolase confers ethnicity-specific risk of myocardial infarction. Nat Genet 2006, 38:68-74.

4. Meschia JF, Brott TG, Brown RD Jr: Crook R, Worrall BB, Kissela B, Brown WM, Rich SS, Case LD, Evans EW, Hague S, Singleton A, Hardy J: Phosphodiesterase 4D and 5-lipoxygenase activating protein in ischemic stroke. Ann Neurol 2005, 58:351-361.

5. Zhang WL, Yang XM, Shi J, Sun K, Hui RT: Polymorphism of SG13S114T/A in the ALOX5AP gene and the risk for stroke in a large Chinese cohort. Acta Genetica Sinica 2006, 33:678-684.

6. Zee RY, Cheng S, Hegener HH, Erlich HA, Ridker PM: Genetic variants of arachidonate 5-lipoxygenase-activating protein, and risk of incident myocardial infarction and ischemic stroke: a nested case-control approach. Stroke 2006, 37:2007-2011.

7. Kostulas K, Gretarsdottir S, Kostulas V, Manolescu A, Helgadottir A, Thorleifsson G, Gudmundsson LJ, Thorsteinsdottir U, Gulcher JR, Stefansson K, Hillert J: PDE4D and ALOX5AP genetic variants and risk for ischemic cerebrovascular disease in Sweden. J Neurol Sci 2007, 263:113-117.

8. Yamada Y, Kato K, Oguri M, Yoshida T, Yokoi K, Watanabe S, Metoki N, Yoshida H, Satoh K, Ichihara S, Aoyagi Y, Yasunaga A, Park H, Tanaka M, Nozawa Y: Association of genetic variants with atherothrombotic cerebral infarction in Japanese individuals with metabolic syndrome. Int J Mol Med 2008, 21:801-808. 
9. Kaushal R, Pal P, Alwell K, Haverbusch M, Flaherty M, Moomaw C, Sekar P, Kissela B, Kleindorfer D, Chakraborty R, Broderick J, Deka R, Woo D: Association of ALOX5AP with ischemic stroke: a population-based casecontrol study. Hum Genet 2007, 121:601-607.

10. Helgadottir A, Gretarsdottir S, St Clair D, Manolescu A, Cheung J, Thorleifsson G, Pasdar A, Grant SF, Whalley LJ, Hakonarson H, Thorsteinsdottir U, Kong A, Gulcher J, Stefansson K, MacLeod MJ: Association between the gene encoding 5-lipoxygenase-activating protein and stroke replicated in a Scottish population. Am J Hum Genet 2005, 76:505-509.

11. Wang X: The diagnosis of various types of cerebral vascular disease. Chin J Neurol 1996, 12:379.

12. Xu ML, Zhang SY, Zhang C, Ma MJ, Zhang LM, Liang QC: Association between the SNPs of ALOXSAP and cerebral infarction in a northern Chinese Han population. Journal of Harbin Medical University 2010, 44(4):326-329.

13. Zintzaras E, Rodopoulou P, Sakellaridis N: Variants of the arachidonate 5lipoxygenase-activating protein (ALOX5AP) gene and risk of stroke: a HuGE gene-disease association review and meta-analysis. Am J Epidemiol 2009, 169:523-532.

14. Yandava CN, Kennedy BP, Pillari A, Duncan AM, Drazen JM: Cytogenetic and radiation hybrid mapping of human arachidonate5-lipoxygenaseactivating protein (ALOX5AP) to chromosome 13q12. Genomics 1999, 56:131-133.

15. Libby P, Ridker PM, Maseri A: Inflammation in atherosclerosis. Circulation 2002, 105:1135-1143.

16. Spanbroek R, Grabner R, Lotzer K, Hildner M, Urbach A, Ruhling K, Moos MP, Kaiser B, Cohnert TU, Wahlers T, Zieske A, Plenz G, Robenek H, Salbach P, Kuhn H, Radmark O, Samuelsson B, Habenicht AJ: Expanding expressing of 5-lipoxygenase pathway within the arterial wall during human atherosclerosis. Pro Natl Acad Sci U S A 2003, 100:1238-1243.

17. Caiming $L$, Cheng Z: The genetics research progress of cerebrovascular disease. J Stroke Nervous Dis 2004, 4:185-187. in Chinese.

18. De Caterina R, Zampolli A: From asthma to atherosclerosis-5lipoxygenase, leukotrienes, and inflammation. N Engl J Med 2004, 350:4-7.

19. Evans JF, Ferguson AD, Mosley RT, Hutchinson JH: What's all the FLAP about?: 5-lipoxygenase-activating protein inhibitors for inflammatory diseases. Trends Pharmacol Sci 2008, 29:72-78.

20. Linsel-Nitschke P, Götz A, Medack A, König IR, Bruse P, Lieb W, Mayer B, Stark K, Hengstenberg C, Fischer M, Baessler A, Ziegler A, Schunkert H, Erdmann J: Genetic variation in the arachidonate 5-lipoxygenaseactivating protein (ALOX5AP) is associated with myocardial infarction in the German population. Clin Sci (Lond) 2008, 115:309-315.

21. Ji R, Jia J, Ma X, Wu J, Zhang $Y, X u L:$ Genetic variants in the promoter region of the ALOX5AP gene and susceptibility of ischemic stroke. Cerebrovasc Dis 2011, 32:261-268.

22. Horvath $\mathrm{S}, \mathrm{Xu} X$, Laird NM: The family based association test method: strategies for studying general genotype-phenotype associations. Eur $\rfloor$ Hum Genet 2001, 9:301-306.

doi:10.1186/1471-2350-13-61

Cite this article as: Zhang et al: Association of ALOX5AP gene single nucleotide polymorphisms and cerebral infarction in the Han population of northern China. BMC Medical Genetics 2012 13:61.

\section{Submit your next manuscript to BioMed Central and take full advantage of:}

- Convenient online submission

- Thorough peer review

- No space constraints or color figure charges

- Immediate publication on acceptance

- Inclusion in PubMed, CAS, Scopus and Google Scholar

- Research which is freely available for redistribution

Submit your manuscript at www.biomedcentral.com/submit
C Biomed Central 